Investigaciones geográficas, $n .^{\circ} 45$ (2008) pp. 63-91 ISSN: 0213-4691
Instituto Universitario de Geografía Universidad de Alicante

\title{
EL MEDIO RURAL EN LA AGENDA EMPRESARIAL: LA DIFÍCIL TAREA DE HACER PARTÍCIPE A LA EMPRESA DEL DESARROLLO RURAL
}

\author{
Juan Cruz Alberdi Collantes \\ Departamento de Geografía \\ Universidad del País Vasco
}

El proyecto que presentamos parte de unos planteamientos ambiciosos e innovadores en el campo del desarrollo rural. Se trata de un trabajo que ha ido conformando sus límites y objetivos a tenor de los resultados que se iban obteniendo en las reflexiones e investigaciones desarrolladas. El objetivo específico con el que se inicia es el diseño de un certificado del compromiso de la empresa con el medio rural, con el objeto de avanzar en la corresponsabilización y el compromiso de la empresa en el mantenimiento del medio rural ${ }^{1}$.

El proyecto que presentamos forma parte de una iniciativa más amplia de sensibilización de la sociedad hacia el medio rural con acciones innovadoras e integrales, dirigidas a la sociedad en general y a diversos ámbitos y colectivos como los vinculados a los centros de formación de distintos niveles, la tercera edad, la familia o la administración comarcal. Sin embargo, tiene en la concienciación y la participación económica de la empresa en proyectos de desarrollo rural su aspecto más novedoso y complicado de materializar.

En su realización se ha optado por tomar un valle como referencia, el Deba, que comprende a las comarcas del Alto y Bajo Deba. Es un valle industrial, con un fuerte tejido empresarial pero con un medio rural, representado

1. A lo largo de las siguientes páginas se pretende sintetizar los resultados de un trabajo promovido por las Asociaciones de Desarrollo Rural del Territorio de Gipuzkoa, el instituto Tecnológico Agrario de la Comunidad Autónoma Vasca (Mendikoi) y el Departamento de Geografía de la Universidad del País Vasco 
por el caserío y pequeños barrios rural que se desarrolla una vez superado el continuo urbano que se extiende por el fondo de su valle.

El presente trabajo pretende recoger a modo de memoria los resultados de las reflexiones desarrolladas en torno a la factibilidad de un certificado de compromiso de la empresa con el medio rural, y concluir con una serie de recomendaciones sobre las actividades a desarrollar para avanzar en la corresponsabilización de la empresa con el medio rural.

\section{Las Asociaciones de Desarrollo Rural, responsables de la promoción del medio rural en el País Vasco}

La iniciativa se enmarca en la trayectoria de promoción del medio rural impulsada desde las instituciones vascas, cuya máxima expresión fue la aprobación por unanimidad en el Parlamento de la ley 10/1998 de 8 de abril de desarrollo rural.

La ley parte del pleno reconocimiento por parte de las instituciones vascas del papel multifuncional que ha de jugar el medio rural en el conjunto de la sociedad vasca. Un espacio rural multifuncional es «aquel que genera renta y empleo; que protege el medio ambiente, la naturaleza y el paisaje; que favorece la gestión equilibrada del territorio; que garantiza la pervivencia de las comunidades rurales y que contribuye a mantener una cultura y una forma de vida que le son propios».

La ley pretende promover una discriminación positiva hacia el medio rural en la búsqueda de un mayor equilibrio territorial del país y mayor equidad en la relación con el mundo urbano, creando las condiciones necesarias para frenar su despoblamiento y atraer nuevos residentes y nuevas actividades.

Profundizando en los objetivos que la norma establece cabe diferenciar en primer lugar la consecución de fines de carácter genérico, habituales en todos los programas de desarrollo rural, entre los que cabe resaltar la necesidad de fomentar la multifuncionalidad y la sostenibilidad del conjunto de su medio rural, preservar sus señas de identidad fundamentales, incrementar la competitividad de las empresas y estructuras económicas de las zonas rurales, integrar las normas y actuaciones de las diferentes administraciones y entidades públicas que afecten al desarrollo de las zonas rurales, y mantener el protagonismo de su desarrollo en su población.

La consecución de los objetivos generales se concreta en la materialización de toda una serie de objetivos específicos o sectoriales. Entre otros, se definen propósitos en materia de ordenación del territorio, en promoción de la agricultura y silvicultura, diversificación del tejido económico del espacio rural y la creación de empleo, dotación educativa y cultural, servicios sanitarios, 
promoción de vivienda, dotación de infraestructuras, desarrollo del turismo o en materia de medio ambiente.

El modelo organizativo que propone la ley de Desarrollo rural no presenta novedades importantes, al menos en un primer momento, respecto a otros programas de desarrollo rural que ya están en marcha en este territorio. En este sentido la norma señala que las políticas orientadas de manera específica al desarrollo de las zonas rurales del País Vasco adoptarán la forma de programas de desarrollo rural. En la elaboración de estos programas se elige la comarca como ámbito preferente de actuación, por la convicción de que el nivel comarcal se muestra como el más adecuado para emprender tal labor puesto que habitualmente se trata de un espacio cohesionado, con una relación funcional manifiesta y con una problemática socioeconómica similar. La elección de este ámbito junto a la necesidad de desarrollar programas de actuación no es sino una continuación del sistema creado a raíz de la aprobación de la ley de Agricultura de Montaña por la Comunidad Autónoma en 1986.

Los nuevos Planes de Desarrollo Rural (PDR) pretenden poner en marcha un proceso gradual y paulatino en el que partiendo del conocimiento y asunción de las especificidades de las distintas zonas rurales del País Vasco se definan las estrategias y actuaciones concretas que es preciso impulsar con el fin de promover el desarrollo integral de la comarca o zona rural considerada.

La realización del Plan, asimismo, ha de contar con las garantías suficientes para ser llevado a cabo en el día a día y, en función de los resultados, que vaya siendo permanentemente adaptado, motivando el aprendizaje organizacional y la participación cada vez de un mayor número de personas. En esta línea, la estrategia de acción planteada se apoya en un proceso de planificación anual, evitando que se trabaje sin continuidad entre el corto y el largo plazo.

La principal novedad que presenta la ley de Desarrollo rural es la asunción de competencias y la programación de la colaboración y coordinación entre las distintas administraciones ${ }^{2}$. Entre la asunción de competencias cabe resaltar la necesidad de que tanto el Gobierno como las diputaciones y ayuntamientos han de participar en la elaboración de los Planes de Desarrollo Rural puesto que su aprobación lleva implícita una obligatoriedad de aceptación y de ejecución en el ámbito de competencia de cada institución. Es más, cada

2. Responde a la cada vez mayor demanda de la población que vive de forma continuada en el medio rural y que está condicionada por el envejecimiento generalizado de sus habitantes. Es una demanda común de las zonas rurales. Reinoso y Sancho (2002) apuntan a los servicios públicos como los más demandados en la Sierra Norte de Guadalajara, especialmente a la mejora de la asistencia sanitaria y en segundo lugar al incremento del transporte público. 
Plan es aprobado en el Parlamento y una vez superado este paso adquiere carácter de decreto y con ello la posibilidad de limitar la ejecución de actuaciones sobre este medio que no respeten lo señalado en los PDR.

Las labores de coordinación y colaboración entre las distintas instituciones la ejerce Landaberri, en cuyo seno se produce la cooperación y colaboración necesarias para la aplicación de la presente ley. Está adscrito al Departamento del Gobierno vasco recayendo la presidencia y la responsabilidad de coordinación en el área de Agricultura y Desarrollo Rural. Está formada por representantes del Gobierno vasco, las diputaciones forales y los municipios de la Comunidad Autónoma. Entre sus funciones cabe destacar la obligatoriedad que tiene de informar sobre las propuestas que se hagan en los Planes de Desarrollo Rural previamente a su elaboración, al mismo tiempo que se le ha de informar sobre aquellos proyectos de ley, decretos, planes o programas de instituciones públicas que afecten de manera importante a las zonas recogidas en los PDR, reservándose el derecho de vetarlas si los miembros de Landaberri así lo decidieran. De igual modo, le compete formular y proponer recomendaciones e iniciativas en torno a la ejecución de los PDR. Landaberri es la encargada de elaborar los programas de desarrollo rural, labor que la realiza a partir de la entidad responsable de la coordinación del desarrollo rural en la Comunidad Autónoma Vasca, Mendikoi, entidad que ya ha acometido la dirección y ejecución de los diferentes programas LEADER ${ }^{3}$.

Si Landaberri o las Landas territoriales son los órganos que han de cumplir la función de coordinar y dirigir las actuaciones en materia de desarrollo rural, la aplicación de los programas diseñados en cada comarca es realizada por órganos locales. En este sentido, se apuesta por la creación de una nueva figura, las Asociaciones de Desarrollo Rural, que se establecen como instrumento de participación y colaboración de los agentes económicos y sociales en las actuaciones de desarrollo rural. La ley establece los requisitos para el reconocimiento de las ADR con el carácter de entidades de derecho privado y representativas de los diferentes sectores económicos y sociales de la zona comprendida en un PDR. Estas asociaciones vienen a dar continuidad a las anteriores Asociaciones de Agricultura de Montaña ${ }^{4}$ que ya existían en las

3. En 1994 se constituyó el Centro Integral para la Formación y la Promoción del Medio Rural de la Comunidad Autónoma del País Vasco MENDIKOI S.A. sociedad pública con entidad jurídica propia dependiente del Departamento de Industria, Agricultura y Pesca del Gobierno Vasco. Corbera (1999) resalta entre sus funciones, la de contribuir activamente a la satisfacción de las necesidades de innovación y de desarrollo integral del medio rural vasco, que transcienden el marco del programa LEADER.

4. A diferencia de otras regiones de España en las que el programa de Agricultura de Montaña no ha funcionado y han sido los LEADER los que han estructurado una política de 
diferentes comarcas y que se ven ahora reforzadas con la asunción de nuevas competencias otorgadas con la aprobación de los PDR comarcales y con su designación como responsables de la ejecución de sus contenidos.

Las ADR firmarán convenios de colaboración para establecer su participación en la puesta en marcha de las actuaciones comprendidas en los PDR correspondientes. Son, por tanto, la herramienta básica en el desarrollo de las medidas y actuaciones recogidas en los Planes de Desarrollo Rural, canalizando los fondos públicos que se designen para tales objetivos.

Pensando en el necesario compromiso de la sociedad con el mantenimiento del medio rural, en el año 1998 se firmó el Pacto Social para el Desarrollo del Espacio Rural. Este Pacto tuvo numerosas adhesiones, y a los cinco años de su aprobación, en 2003, se consideró conveniente recordar el espíritu y voluntad de la ley, y recordar a la sociedad vasca el compromiso con el medio rural recogido en el mismo. Supuso de nuevo «la escenificación» de un primer nivel de implicación con el medio rural y comprensión de la necesaria corresponsabilización del conjunto de la sociedad con el mantenimiento y desarrollo del medio rural vasco, lográndose la adhesión de un buen número de agentes económicos y sociales, públicos y privados.

Con el diseño y puesta en marcha de un certificado de compromiso de la empresa con el medio rural, se pretende «dar un paso más» en la línea de la corresponsabilización y la sensibilización hacia el medio rural por parte de un agente o público objetivo específico, la empresa. Se pretende diseñar un sistema, método o herramienta que facilite la materialización del Pacto por parte de las firmas privadas, la asunción de compromisos concretos por parte de éstas y su visualización y reconocimiento por el conjunto de la sociedad vasca.

\section{La obtención de un certificado de compromiso, objetivo inicial}

En el enfoque del proyecto y su desarrollo metodológico se han tenido en cuenta una serie de premisas e hipótesis de partida. Entre las más relevantes destacamos, en primer lugar, las previsibles dificultades de las compañías privadas no vinculadas directamente al sector agrario o agroalimentario para comprender, interpretar o «visualizar», cuál es su relación con el medio rural (impactos positivos y negativos), de qué manera pueden contribuir a su mantenimiento y desarrollo y cuál es la responsabilidad que les corresponde.

desarrollo rural (Cruz, 2000), en el País Vasco estas estructuras han ido progresivamente incorporando programas y servicios y se convierten ahora en herramienta básica en la ejecución de estos programas. 
En segundo lugar, una posible «resistencia», o cuando menos falta de interés, por parte de las empresas hacia la incorporación de un nuevo sistema de reconocimiento que exija compromisos en su actuación ${ }^{5}$. En este sentido, en el diseño del certificado de compromiso con el medio rural, se consideraba fundamental valorar el nivel y complejidad de las exigencias, la carga burocrática que pueda suponer la aplicación de un posible reglamento y su posterior evaluación, la posibilidad de sinergia con otros compromisos y criterios de actuación de la empresa, con otros sistemas (ISO, EFQM,...), las ventajas derivadas para la empresa y beneficios esperados, los mecanismos de incentivación, etc.

En cualquier caso, a favor de un potencial certificado de compromiso de la empresa con el medio rural también detectábamos a priori dos aspectos diferenciados, como era la posible idoneidad de que la sensibilización de la empresa privada hacia el medio rural vasco se plantease a través de herramientas conocidas, llegando a ellas a través de un lenguaje que les resulta cercano (ISO, EFQM, memorias de sostenibilidad, etc.). Considerábamos interesante el establecimiento de un certificado de compromiso que fuera integrable al resto de reconocimientos ya disponibles en el ámbito empresarial ${ }^{6}$.

Por otro lado, apuntábamos el contexto favorable en el que se plantea la iniciativa, en el que en mayor o menor medida la empresa es consciente de la necesidad de actuar con criterios de sostenibilidad y donde la responsabilidad social corporativa está adquiriendo una importancia creciente. Cada vez es menos extraño escuchar conceptos como el código de conducta de las empresas, los valores, la cultura de compromiso con el entorno social ${ }^{7} \ldots$

5. Algunos economistas liberales, como Milton Friedman (1994), consideran que la única responsabilidad social de la empresa debe ser la generación de ganancias en favor de sus dueños, accionistas y trabajadores en un marco de competencia libre y abierta. Si la empresa sacrificase ganancias en nombre de la responsabilidad social -piensa Friedman- sería menos atractiva para inversionistas, trabajadores y consumidores, y a la larga perecería frente a los competidores.

6. «La empresa desempeña un papel muy importante en la vida de las personas no sólo como generadora de empleo y de riqueza, sino como agente de desarrollo en las comunidades en la que están insertas. Las grandes empresas son conscientes de ello y aprovechan las expectativas que genera la responsabilidad social corporativa para obtener ventajas competitivas (ayudan ayudándose). La filantropía corporativa ha dejado de ser una actividad autónoma confiada a una fundación y cada vez más forma parte de las estrategias que contribuyen a realizar el objeto social de la empresa» [en línea], <http:// es.wikipedia.org/wiki/responsabilidad_social_corporativa>. [Consulta: 8/04/2008].

7. Una empresa es socialmente responsable cuando responde satisfactoriamente a las expectativas que sobre su funcionamiento tienen los distintos grupos de interés. La responsabilidad social empresarial se refiere a cómo las empresas son gobernadas respecto a los intereses de sus trabajadores, sus clientes, proveedores, sus accionistas y su impacto 
Bajo estas consideraciones y teniendo en cuenta la complejidad de diseñar e implantar un certificado de compromiso de la empresa con el medio rural el proyecto se plantea con un enfoque metodológico en el que, independientemente del resultado (factibilidad de un certificado de compromiso de la empresa con el medio rural), el propio proceso de estudio constituya una aportación de valor al proyecto global de sensibilización y concienciación hacia el mantenimiento del medio rural.

Así, el trabajo realizado se concreta en dos fases principales:

- Análisis comparativo de los distintos sistemas de gestión, certificados, etc. que se manejan actualmente en el mundo empresarial y que en principio pudieran tener alguna relación con el compromiso de la empresa con el medio rural.

- Informe de posicionamiento de las firmas en torno a un certificado de compromiso con el medio rural a partir de entrevistas con gerentes y responsables de una muestra de compañías de ambas comarcas. Con este trabajo de campo no sólo conoceremos de primera mano la opinión de las empresas y testaremos la validez de nuestras hipótesis de partida, sino que también propiciaremos la oportunidad de un primer contacto entre éstas y las Asociaciones de Desarrollo Rural. Este contacto habrá de servir para captar información pero también para la transmisión de una serie de mensajes dirigidos a informar y sensibilizar a la empresa sobre la importancia del medio rural para el conjunto de la sociedad, la necesidad de corresponsabilizarse en su mantenimiento, la existencia de instrumentos y mecanismos de apoyo al medio rural, etc. La entrevista se convierte de este modo en un vehículo de información-comunicación y sensibilización de la empresa, mientras se sondea su opinión en torno a la factibilidad de un hipotético certificado de compromiso con el medio rural.

Dentro del proceso de trabajo los resultados de las entrevistas a las empresas y el consiguiente informe de posicionamiento constituyen un hito fundamental en el proyecto ya que condicionan de forma importante los siguientes pasos, así como las perspectivas de futuro de una iniciativa que, en última instancia, lo que pretende es ahondar en la corresponsabilización con

ecológico y social en la sociedad en general, es decir, a una gestión de la empresa que respeta a todos sus grupos de interés y supone un planteamiento de tipo estratégico que debe formar parte de la gestión cotidiana de la toma de decisiones y de las operaciones de toda la organización, creando valor en el largo plazo y contribuyendo significativamente a la obtención de ventajas competitivas duraderas. De ahí la importancia de que tanto los órganos de gobierno como la dirección de las empresas asuman la perspectiva de la responsabilidad social empresarial». Foro de Expertos de la RSE, Ministerio de Trabajo y Asuntos Sociales, 2008. 
el mantenimiento del medio rural. Se exponen a continuación los principales resultados de este trabajo, principales conclusiones y propuestas para avanzar en este objetivo.

\section{El medio rural se puede beneficiar de los sistemas y certificados de gestión empresarial}

Llevamos décadas asistiendo a la progresiva adopción por parte de las empresas de sistemas de gestión de la calidad y del medio ambiente como garantía, ante el cliente y la sociedad en general, de la actuación de la entidad en relación a la calidad en los servicios prestados y el respeto medioambiental de las actuaciones llevadas a cabo por la misma.

Las empresas concretan y hacen público su compromiso a través de sus políticas de calidad y medio ambiente y la certificación correspondiente al sistema de gestión elegido: ISO 9001, puntuación en el modelo de autoevaluación $\mathrm{EFQM}$, ISO 14001, etc 8 .

Más reciente es el concepto de responsabilidad social empresarial (RSE) que se define como «la integración voluntaria, por parte de las empresas de las preocupaciones sociales y medioambientales en sus operaciones comerciales y sus relaciones con sus interlocutores».

En la medida en que con el presente proyecto se pretende diseñar algún tipo de sistema, reconocimiento o certificado de compromiso con el medio rural por parte de la empresa, se ha considerado oportuno realizar un análisis comparativo sobre lo que implican para la empresa, tanto los principales sistemas de gestión ambiental introducidos en el panorama empresarial del País Vasco como la RSE.

Se presenta a continuación una síntesis de los análisis realizados orientados a identificar la existencia de posibles sinergias y la oportunidad de ligar o apoyar un hipotético certificado de compromiso de la empresa con el medio rural a certificados, sistemas o compromisos ya existentes.

8. Son muchos los programas generados en torno a estas cuestiones. Por ejemplo, en la Fundación Ecología y Desarrollo proponen que las empresas deben de jugar un papel activo en la resolución de los retos que plantea alcanzar un desarrollo económico, social y ambiental más sostenible. Por ello en 1999 se creó el Programa de Economía y Responsabilidad Social Empresarial (Ecores) con el objetivo de conseguir que las empresas y productos más respetuosos con el medio ambiente y la sociedad sean reconocidos por el mercado, que el compromiso con el desarrollo sostenible se convierta en un factor de éxito empresarial y que, por tanto, las empresas tengan incentivos no sólo éticos sino también económicos para actuar más responsablemente (Ecología y Desarrollo, 2008). 
3.1. Las cuestiones ambientales, las más identificadas en los sistemas de gestión empresarial

A lo largo de este apartado se presentan una serie de tablas en las que se pretende sintetizar la información clave (objetivos, ámbitos en los que opera, criterios, beneficios derivados, etc.) de los siguientes certificados o sistemas de gestión empresarial: sistemas de gestión ambiental (SGA): ISO 14001 y responsabilidad social empresarial (RSE).

En relación a los sistemas de gestión ambiental, la evolución experimentada en el número de certificaciones Iso 14001 da idea del interés creciente de las empresas, no sólo por mejorar su comportamiento medioambiental, sino también por obtener un reconocimiento a los esfuerzos realizados en pro del medio ambiente.

En términos generales la aplicación de estos sistemas puede generar los siguientes beneficios para las empresas:

- Minimización de los gastos. Reducción del consumo de energía, de gastos de materia prima, gastos para la eliminación de residuos.

- Aumento de la competitividad. Responder convenientemente a las demandas de los consumidores, ONG, accionistas y otros, mejorar la imagen de la empresa o ventajas para conseguir créditos en condiciones más favorables.

- Disminución de los riesgos por incremento de la seguridad laboral.

- Desarrollo organizacional. Reconocer los puntos débiles y obtener información adecuada para el caso de emergencia ambiental.

Desarrollamos en la tabla 1 cuáles son los ámbitos en los que opera la norma ISO 14001, la que mayor interés ha suscitado entre las empresas a la hora de poner en marcha un proceso de implementación de un sistema de gestión ambiental.

La responsabilidad social empresarial (RSE), parte de una concepción diferente. La supervivencia de la empresa se basa en generar máximo beneficio a los accionistas. Sin embargo, los criterios sociales influyen cada vez más en las decisiones de inversión de las personas y de las instituciones. Los impactos sociales, ambientales y económicos que producen las organizaciones cada vez tienen más importancia y los clientes y proveedores manifiestan nuevas inquietudes y expectativas.

Las organizaciones, hoy, tienen que «ganarse» a la sociedad para perdurar en el negocio. Muchas ya están comprometidas con los grupos de interés y contribuyen a la sociedad. Forma parte de su filosofía. La RSE no es algo que 
Tabla 1. Sistemas de gestión ambiental IsO 14001

\begin{tabular}{|c|c|c|}
\hline DEFINICIÓN & \multicolumn{2}{|c|}{$\begin{array}{l}\text { - Su función principal es auxiliar el proceso de implementación de un Sistema de } \\
\text { Gestión Ambiental ( SGA), que a su vez tenga como principio la mejora continua del } \\
\text { desempeño ambiental de la empresa hasta los niveles deseados. }\end{array}$} \\
\hline \multicolumn{3}{|c|}{ ÁMBITO EN EL QUE OPERA } \\
\hline \multirow{6}{*}{ AMBIENTAL } & \multicolumn{2}{|c|}{$\begin{array}{l}\text { - Le confiere un carácter pro-activo y estimula el desarrollo de todas las funciones } \\
\text { de la empresa, desde el más alto cargo de dirección y gerencia, hasta los niveles } \\
\text { operacionales. } \\
\text { - El compromiso debe comprobarse no sólo para la formulación de la política } \\
\text { ambiental de la empresa sino también durante todo el proceso de identificación y } \\
\text { evaluación de los impactos ambientales causados por el proceso productivo, por } \\
\text { sus productos o servicios suministrados, así como sus revisiones. } \\
\text { - Son establecidas } 5 \text { etapas de implementación o requisitos que serán objetivamente } \\
\text { verificados durante un proceso de auditoria de los sistemas de gestión ambiental: }\end{array}$} \\
\hline & - Política ambiental & $\begin{array}{l}\text { - Adecuación a la naturaleza, escala e impactos de sus } \\
\text { actividades, productos o servicios. } \\
\text { - Compromiso con la legislación, principios de } \\
\text { prevención y de mejoría continua. } \\
\text { - Claridad que permita el establecimiento de objetivos } \\
\text { y metas. } \\
\text { - Documentación y comunicación entre los } \\
\text { funcionarios. } \\
\text { - Disponibilidad con la comunidad externa. }\end{array}$ \\
\hline & - Planificación & $\begin{array}{l}\text { - Identificación de aspectos ambientales. } \\
\text { - Requerimientos legales y otros. } \\
\text { - C. Objetivos y metas ambientales. } \\
\text { - Programa de gestión ambiental. }\end{array}$ \\
\hline & $\begin{array}{l}\text { - Implementación } \\
\text { operación }\end{array}$ & $\begin{array}{l}\text { - Puesta en marcha de acciones encaminadas a } \\
\text { minimizar el impacto de los aspectos contaminantes. } \\
\text { Aspectos medioambientales: "Elementos de las } \\
\text { actividades de una organización que pueden } \\
\text { interactuar con el medio ambiente". } \\
\text { Impacto ambiental: "Cualquier cambio en el } \\
\text { medioambiente sea adverso o beneficioso, } \\
\text { resultado de las actividades de una organización". } \\
\text { Comportamiento medioambiental: "Resultados } \\
\text { medibles del sistema de gestión medioambiental } \\
\text { relativos al control de la organización de sus } \\
\text { aspectos medioambientales basados en su } \\
\text { política medioambiental, sus objetivos y sus } \\
\text { metas". } \\
\text {-Prevención de la contaminación. } \\
\text {-Cumplimiento legislativo. }\end{array}$ \\
\hline & $\begin{array}{l}\text { - Verificación y acciones } \\
\text { correctivas }\end{array}$ & $\begin{array}{l}\text { - Monitoreo y medición. } \\
\text { - Disconformidades y acción preventiva y correctiva. } \\
\text { - Registros. }\end{array}$ \\
\hline & $\begin{array}{l}\text { - Auditoría del SGA y nuevo } \\
\text { análisis }\end{array}$ & -Mantenimiento del SGA. \\
\hline
\end{tabular}

añade a la actividad principal de la empresa, sino que es algo intrínseco a la misma y debe estar integrada en la estrategia y gestión de la misma9

9. En la Cumbre de Lisboa del 23 y 24 de marzo de 2000, la Unión Europea estableció para la siguiente década el objetivo estratégico de convertirse en «la economía más competitiva y dinámica, basada en el conocimiento, capaz de un crecimiento económico sostenible con más y mejores empleos y una mayor cohesión social», haciendo por primera vez una llamada expresa a las empresas en torno a su responsabilidad social. Unos meses después, el Consejo Europeo de Feira de junio de 2000 acordó iniciar un proceso de diálogo europeo para la promoción de la responsabilidad social corporativa. Con la publicación del Libro verde: Fomentar un marco europeo para la responsabilidad social de las empresas en julio de 2005 (en adelante, el Libro verde) y la petición de comentarios a todas las partes interesadas, la Unión Europea ha abierto el debate a escala 
Corresponde a todos los tipos de empresa y en todos los sectores de actividad, desde las pymes hasta a las empresas multinacionales; todas ellas prestan atención a aspectos ambientales y sociales.

Para profundizar y extraer los rasgos e implicaciones más importantes de la RSE se han utilizado los planteamientos realizados por EFQM, que ha elaborado en 2004 un marco en coherencia con el modelo EFQM, e IZAITE, Asociación de Empresas Vascas por la Sostenibilidad, que nace en 2003 con el objetivo de constituir un foro de diálogo entre organizaciones privadas que permita el impulso del desarrollo sostenible desde el sector empresarial compartiendo prácticas para contribuir a la excelencia de las empresas y al progreso de la sociedad. La Asociación está compuesta por ACB, BBK, Energía Portátil, Grupo Eroski, Euskaltel, Fagor Electrodomésticos, Iberdrola, ITP y Ofita, además de Euskalit e IHOBE (véase tabla 2).

En nuestra comunidad, La RSE es un concepto poco conocido $^{10}$, no es prioritario para las empresas, siendo las cuestiones que identifican con más facilidad con la RSE las ambientales y la mejora de las relaciones laborales. Aquellas que muestran un conocimiento tienen la impresión de que el desarrollo de políticas de RSE contribuiría positivamente en dos ámbitos de su organización como son la mejora de las relaciones con el entorno o con la sociedad y la mejora de la imagen de su empresa. Sin embargo, no la contemplan como una posibilidad de mejora de competitividad, consideran que su fomento ha de venir de la mano de la recomendación y no de la regulación y que han de ser los agentes institucionales y asociaciones empresariales los promotores de sus acciones.

\subsection{La corresponsabilidad rural converge preferentemente con la RSE}

Tras analizar los sistemas de gestión empresarial que más se podían adecuar a nuestra idea de lo que pudiera ser una corresponsabilidad en el desarrollo

comunitaria, susceptible de dar lugar a una iniciativa legislativa sobre el tema. En el Libro Verde, la responsabilidad social de las empresas se define como la «integración voluntaria, por parte de las empresas, de las preocupaciones sociales y medioambientales en sus operaciones comerciales y sus relaciones con sus interlocutores» (Unión Europea, 2001, página 7).

10. La primera conclusión que podemos extraer del alcance del concepto de la responsabilidad social, como señala Benbeniste (2002) es que se trata de un concepto en desarrollo, no cristalizado. La mayoría de las instituciones internacionales esquivan elaborar una definición del mismo, o cuando lo hacen, le brindan una dimensión puramente operativa. Además, muchas organizaciones adoptan un enfoque pragmático, equiparando el término RSC a otros conceptos relacionados, como sostenibilidad o ciudadanía corporativa 
Tabla 2. Responsabilidad Social Empresarial

\begin{tabular}{|c|c|}
\hline \multicolumn{2}{|c|}{ RESPONSABILIDAD SOCIAL EMPRESARIAL } \\
\hline IZATE & EFQM \\
\hline $\begin{array}{l}\text { RSE COMO ELEMENTO DIFERENCIADOR } \\
\text { - Mejora la imagen corporativa, de su reputación pública. Se } \\
\text { incrementa la notoriedad y produce una influencia positiva de la } \\
\text { empresa en la sociedad. } \\
\text { - Los clientes actuales toman conciencia de su empresa } \\
\text { proveedora y consecuentemente incrementan su atractivo por la } \\
\text { empresa socialmente responsable y son más fácilmente fidelizables. } \\
\text { - Mejora de la relación de la empresa con el entorno. La } \\
\text { actuación de la empresa sobre conceptos de RSE, le permiten una } \\
\text { mejor estrategia de comunicación, la sociedad en general está } \\
\text { más predispuesta a los mensajes de empresas políticas socialmente } \\
\text { reconocidas. }\end{array}$ & $\begin{array}{l}\text { - Incremento del valor de marca. } \\
\text { - Acceso mayor a fuentes de financiación. } \\
\text { - Un personal más saludable y seguro. } \\
\text { - Un gobierno corporativo y gestión de riesgo más robusto. } \\
\text { - Personal motivado. } \\
\text { - Clientes fidelizados. } \\
\text { - Elevada confianza y credibilidad de los grupos de interés. } \\
\text { - Una imagen pública más reforzada. }\end{array}$ \\
\hline $\begin{array}{l}\text { COMO FACTOR DE MEJORA DEL CLIMA LABORAL } \\
\text {-Se pueden derivar resultados positivos de un mejor entorno de } \\
\text { trabajo, que genere un mayor compromiso de los trabajadores y } \\
\text { de ello se mejore la productividad. } \\
\text { - Se fomenta una cultura corporativa, que redunda } \\
\text { fundamentalmente en la gestión de los recursos utilizados en la } \\
\text { actividad empresarial, abriendo así una vía para administrar el } \\
\text { cambio y conciliar el desarrollo social con el aumento de la } \\
\text { competitividad. }\end{array}$ & $\begin{array}{l}\text { Ejemplos de beneficios para los grupos de interés } \\
\text { EMPLEADOS: Incremento de flexibilidad, adaptabilidad y } \\
\text { movilidad. El compromiso con la RSE ayudará a atraer y retener } \\
\text { al personal más apto. } \\
\text { CLIENTES: Cada día pueden optar por más productos y } \\
\text { servicios. Ya comienzan, con tanta variedad, a diferenciar entre } \\
\text { ellos demandando más información relativa a la RSE. A los } \\
\text { clientes les hará sentirse cada vez mejor el hecho de que lo que } \\
\text { compran tiene en cuenta los aspectos sociales y ambientales. }\end{array}$ \\
\hline $\begin{array}{l}\text { CONCLUSIóN: La RSE tiene una influencia positiva en la empresa, } \\
\text { que se puede traducir en mejores ventas, una mayor motivación } \\
\text { de los empleados, el fomento de la innovación, una mayor } \\
\text { confianza del ciudadano y una mejora en la reputación } \\
\text { corporativa y en el posicionamiento en el mercado. }\end{array}$ & $\begin{array}{l}\text { INVERSORES: La tendencia es mirar más allá de los resultados } \\
\text { financieros de las empresas. Por ejemplo, Dow Jones y el } \\
\text { Finacial Times Stock Exchange han desarrollado el índice de } \\
\text { sostenibilidad del Dow Jones y el Finacial Times Stock Exchange } \\
\text { for Good. Como ha constatado el Dow Jones, "un número } \\
\text { creciente de inversores privados e institucionales comparten la } \\
\text { convicción de que la integración de los factores de éxito social, } \\
\text { ambiental y económico en los negocios es una ventaja } \\
\text { competitiva". } \\
\text { PROVEEDORES: Cada vez más, las organizaciones piden más } \\
\text { evidencias de RSE a sus proveedores. Quieren tener la } \\
\text { seguridad de que están comprando productos y servicios que no } \\
\text { van a empañar su reputación y la de sus productos. } \\
\text { SOCIEDAD: La sociedad se beneficia pues los recursos } \\
\text { escasos están mejor destinados y las actividades de las } \\
\text { organizaciones pueden estimular las economías locales o } \\
\text { regionales. La RSE puede conducir el ahorro de costes y } \\
\text { sinergias. Por ejemplo, iniciativas ambientales pueden llevar a } \\
\text { nuevos procesos y sistemas con un coste global más bajo y la } \\
\text { eliminación de desperdicios. }\end{array}$ \\
\hline
\end{tabular}

del medio rural abordamos ahora cuáles han de ser los puntos de referencia, objetivos y ámbitos sobre los que se debe de sustentar una posible implicación en el progreso de las comunidades rurales. Para ello, nos apoyamos en los objetivos que se recogen en la ley de Desarrollo rural, posteriormente ampliados en los diferentes Planes de Desarrollo Rural puesto que consideramos que, de realizarse una propuesta al mundo empresarial, ésta se ha de apoyar en un marco establecido y aceptado por la mayoría. Resumimos en la tabla 3 nuestra idea de lo que debe de ser la corresponsabilidad con el medio rural.

Como se observa, el compromiso de la empresa ha de estar dirigido a apoyar actividades que contribuyan a mantener y promover el espacio rural desde una óptica amplia, que abarque todos los aspectos que contribuyen al desarrollo y a la mejora de la calidad del medio y del habitante rural. Esta definición de la corresponsabilidad con el medio rural y los análisis comparativos realizados con otros sistemas permiten concluir que:

- El compromiso de la firma con el medio rural se concibe como un compromiso voluntario. 
Tabla 3. Qué pretende ser la corresponsabilidad con el medio rural

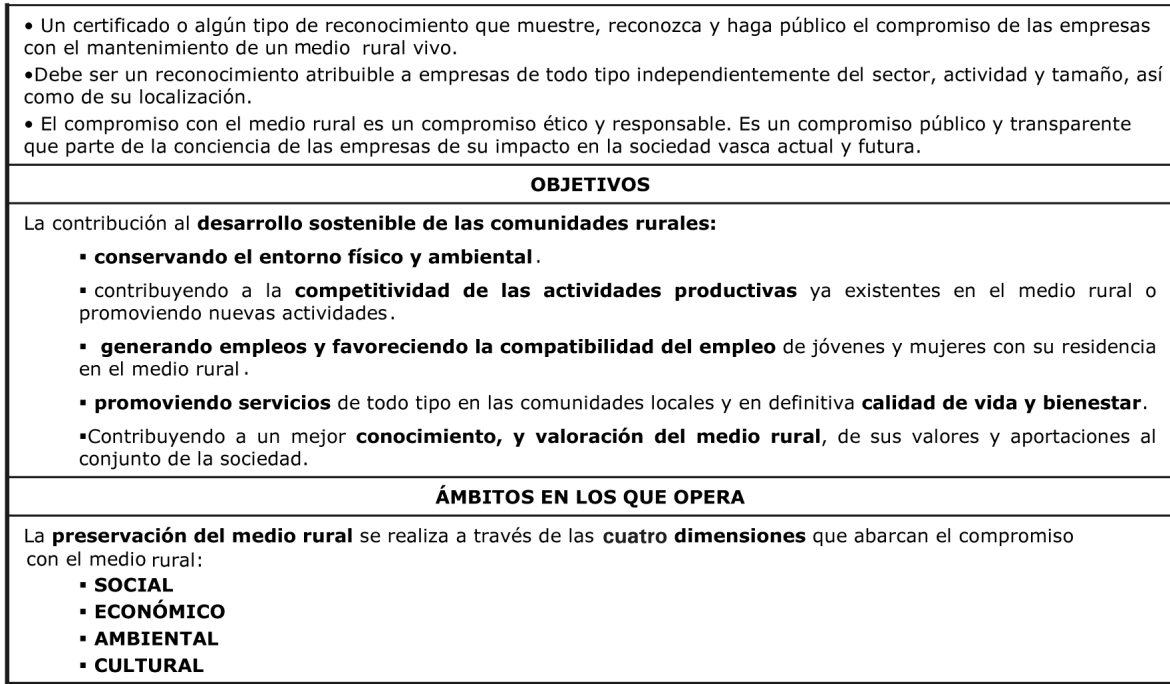

- Es coherente con el compromiso de la empresa por la sostenibilidad y con la RSE entendida como la integración voluntaria de las preocupaciones sociales y medioambientales en la práctica diaria de las empresas y en la interacción con sus agentes de interés (accionistas/dueños, empleados, clientes, medio ambiente, comunidad, suministradores).

- Se vehicula de forma natural a través de la perspectiva externa de la RSE, aquella que se refiere a las relaciones de la empresa con interlocutores externos y su entorno social y medioambiental, en sentido amplio: la comunidad, los interlocutores públicos, las organizaciones no gubernamentales, las entidades de interés social, los consumidores, etc. Lo cual no excluye la posibilidad de desarrollar actuaciones que contemplen los aspectos sociales de la propia actividad de la empresa (recursos humanos, gestión de la calidad, etc.) y que redunden al mismo tiempo en el mantenimiento de un medio rural vivo.

- Es un compromiso más amplio que la responsabilidad con el medio ambiente. Estando en línea con la filosofía de la RSE pone énfasis también en la dimensión económica, social y cultural, dimensiones importantes para la sostenibilidad.

La corresponsabilidad con el medio rural es coincidente preferentemente con la RSE. Este parece ser el campo en el que debemos centrar nuestros esfuerzos y en el que debemos procurar que la empresa contemple sus actuaciones. 
Sin embargo, como hemos señalado, no es éste el concepto prioritario para las compañías, más centradas en las implicaciones ambientales y labores de su actividad que en el desarrollo de variables que mejoren la calidad de vida del conjunto de la sociedad.

\section{Las empresas del valle del Deba rechazan un certificado de compromiso con el medio rural}

Se plantea desde el inicio la idoneidad de una investigación basada en métodos cualitativos y específicamente el desarrollo de entrevistas personales a responsables y directivos de empresa en base a un guión estructurado.

La entrevista se ha desarrollado en una muestra de empresas en cada una de las comarcas que, si bien no responde a criterios estadísticos de representatividad, se considera suficiente tanto por el número de compañías entrevistas como por haberse buscado la opinión de empresas de distintos tamaños, formas jurídicas y actividades productivas presentes en cada una de las comarcas.

Entre ambas comarcas han sido 102 las contactadas entre los meses de septiembre y principios de enero de 2007, que es el período en el que se ha desarrollado el trabajo de campo (55 en Debabarrena y 47 en Debagoiena). A pesar de ello, y por diferentes motivos las entrevistas finalmente realizadas en el período establecido para el trabajo de campo han sido 37.

En el contacto telefónico inicial los entrevistadores se han dirigido al perfil de gerencia en empresas pequeñas, mientras que en entidades de mayor tamaño la solicitud de entrevista ha ido dirigida a los responsables de calidad o responsables de medio ambiente en caso de que lo hubiese. Hay que señalar que no en todos los casos se han podido superar todos los filtros y contactar con la persona deseada o identificar la más idónea para atender un tema de esta índole. En algunos casos el contacto telefónico ha ido acompañado de un E-MAIL de contextualización y presentación del proyecto, anticipo del guión vía correo electrónico, etc.

En cualquier caso se considera que el nivel y tipo de respuesta obtenido es suficientemente clarificador a efectos del presente proyecto, siendo también positivamente valorada la oportunidad que ha supuesto para las ADR el desarrollo de las entrevistas en términos de establecer un contacto hasta ahora inexistente con el tejido empresarial de su comarca, poder darse a conocer y transmitir los objetivos e instrumentos de desarrollo rural y la importancia de la corresponsabilización de todos, incluida la empresa en el mantenimiento de un medio rural vivo.

Las entrevistas realizadas han constituido en la gran mayoría de los casos el primer acercamiento de las firmas a la problemática del medio rural y a los 
mecanismos y agentes que hoy por hoy trabajan por el desarrollo del medio rural en el ámbito de la comunidad autónoma y en el ámbito más cercano de las respectivas comarcas.

\subsection{Dificultad de la empresa para identificar en qué y por qué han de apoyar al medio rural}

Como era de esperar, la gran mayoría de las compañías entrevistadas en ambas comarcas desconocen la ley de Desarrollo rural y los instrumentos existentes en pro del medio rural. Es más, el 100\% de las empresas entrevistadas, tanto en una comarca como en otra, desconocen el Pacto Social, lo que éste implica y por lo tanto, el hecho de que haya algunas empresas que lo han suscrito.

En general, no han oído hablar, específicamente, de los Programas de Desarrollo Rural comarcales ni de las Asociaciones de Desarrollo Rural, sus objetivos y actividades, sin que haya existido ningún tipo de relación o contacto con la ADR de su correspondiente comarca, con carácter previo a esta entrevista. Las escasas excepciones a este resultado general se circunscriben a algunas empresas relacionadas con el mundo agrario así como a las tres empresas que suscribieron el Pacto Social.

La visión que tienen del medio rural y el papel que pueden jugar en su desarrollo se topa con un punto de partida sustentado en dos realidades diferentes. Por un lado, la dificultad que encuentran para comprender qué se entiende por medio rural. Con frecuencia, el mantenimiento del medio rural se identifica con el mantenimiento de la actividad agraria, con el medio ambiente y entorno natural. Por otro, y relacionado con la identificación de mundo rural y mundo agrario, un cierto prejuicio o prevención sobre la necesidad de que la empresa se implique y deba jugar algún papel en su mantenimiento.

En consecuencia, la gran mayoría encuentra dificultades para identificar de manera natural y espontánea las razones por las que la firma debiera implicarse en la preservación del medio rural ${ }^{11}$.

A partir de ahí, y de la labor pedagógica y de comunicación desarrollada por los entrevistadores, entre las razones sugeridas aproximadamente un 60$70 \%$ de las entrevistadas en ambas comarcas coinciden en que la razón más importante por la que deben implicarse en la preservación del medio rural es

11. La organización de la RS está todavía en fase de clarificación y consolidación en las empresas. La incorporación de indicadores es incipiente. No se identifican los riesgos y oportunidades derivadas de la RS ni se realiza un plan de acción basado en ellos. Son aun muy pocas las empresas que realizan los informes, Triple Bottom Line, integrando los aspectos económicos, sociales y medioambientales (Ministerio de Trabajo y Asuntos Sociales de España, 14-03-2008). 
por una «obligación moral» que trasciende del ámbito de la compañía. En la medida en que la preservación del medio rural es responsabilidad de toda la sociedad y nos beneficia a todos, las empresas deberían asumir su parte.

La segunda razón más apoyada, entre las sugeridas, (en torno a un 20$25 \%$ ), es la de proyectar una «imagen» de compromiso con el medio rural ante la sociedad y mejorar, de esta manera, la percepción de ésta sobre la firma y sus actividades.

En torno a un $20 \%$ de los entrevistados sigue sosteniendo que el mantenimiento del medio rural no afecta a la empresa o es una responsabilidad ajena a ella y por lo tanto «no hay ninguna razón» por la que debiera implicarse en esta tarea ${ }^{12}$.

En cuanto a los beneficios o ventajas que puede aportar a una firma el compromiso con el medio rural, nuevamente hay que destacar la ausencia de respuestas espontáneas. Entre las sugeridas por los entrevistadores, las posiciones son variadas, destacando el hecho de que al menos una de cada tres empresas entrevistadas no ve ningún beneficio claro en el compromiso con el medio rural.

A partir de las sugerencias de los entrevistadores, si hubiese que destacar el beneficio por el que opta la empresa con más frecuencia destacaríamos que «demuestra el compromiso con la comunidad y con el entorno», la «mejora de la imagen» y que el compromiso de la compañía con el medio rural puede además reportarle «adhesión y satisfacción de los trabajadores» ${ }^{13}$.

\subsection{Apuesta por la promoción de la corresponsabilidad pero rechazo al certificado entre las empresas del valle del Deba}

Dada la convergencia existente entre responsabilidad social empresarial y el potencial compromiso de la empresa con el mantenimiento del medio rural, se pregunta a las compañías sobre su nivel de conocimiento e implicación con la RSE. De las respuestas obtenidas podemos concluir que el nivel de introducción de la RSE es todavía limitado. En cualquier caso, el nivel de conocimiento es superior entre las entrevistadas en la comarca del Alto Deba que entre las

12. Como señala Canyelles (2006), para una visión de empresas más bien reticentes a un progreso de la RSE en la sociedad y en el mercado, les conviene un estado como el actual, en el que no hay el menor asomo de exigibilidad.

13. Aunque casi todas las empresas encuestadas afirman realizar medidas en el entorno laboral y de trabajo, principalmente guiadas por la legislación, las prácticas voluntarias más innovadoras son aún reducidas. La acción social más extendida en la comunidad local es la asignación de partidas presupuestarias para donaciones u obras de beneficencia (Ministerio de Trabajo y Asuntos Sociales de España, 14-03-2008). 
correspondientes a la comarca vecina, pudiendo influir en este hecho dos variables: el tamaño de las empresas entrevistadas (en el Alto Deba un $46 \%$ son empresas de más de 101 trabajadores) y la fuerte presencia de cooperativas ${ }^{14}$.

Independientemente del conocimiento o introducción de la RSE en la gestión empresarial se les pregunta por actuaciones que han desarrollado o están desarrollando y que demostrarían un compromiso con la sociedad, el medio ambiente y el entorno en general.

Las respuestas obtenidas ponen de manifiesto que la gran mayoría demuestran sensibilidad hacia los temas relacionados con el medio ambiente y especialmente con la minoración del impacto de su actividad empresarial en el entorno, así como la aplicación de políticas de sostenibilidad en sus procesos y una adecuada gestión de los residuos generados por la actividad de la empresa $^{15}$.

Así mismo, un alto porcentaje de compañías colabora en diversas actividades socioculturales de la comarca en la que se encuentra, bien a través de aportaciones económicas a fiestas y actividades culturales, bien patrocinando eventos de diversa índole (actividades y equipos deportivos), impulso del conocimiento y utilización del euskera, etcétera. Las empresas de mayor tamaño colaboran habitualmente con organizaciones sociales, ONG, etc.

Es importante destacar que casi en el 90\% de los casos, salvo en algunas empresas con sistemas de gestión ambiental, estas actuaciones no responden a una política o estrategia específica de la firma, sino que se trata de acciones puntuales de respuesta a demandas de terceros que acuden con solicitudes de apoyo a iniciativas concretas y específicas.

En principio, la actitud de las empresas ante la propuesta de incluir el apoyo al mantenimiento del medio rural entre los objetos de apoyo y demostración de la responsabilidad social de la empresa es positiva. No obstante, les resulta complejo identificar acciones de apoyo concretas y diferentes a la aportación económica para el desarrollo de un determinado proyecto.

14. Las cooperativas, por principios deben contribuir a generar riqueza, promover la justicia social, etc. La colaboración con proyectos RSE se realiza por lo general vía FEPI (5\% de los beneficios). Así por ejemplo, Caja Laboral, uno de los suscriptores del Pacto Social tiene un presupuesto destinado a temas como la promoción de cooperativas, el euskera, el apoyo a las asociaciones del tercer mundo, etc. Se trata de donaciones.

15. Si tomamos como referencia aquellas empresas que la Dirección General de Empresas de la Comisión Europea destaca por su labor en la responsabilidad social, todas ellas centran sus esfuerzos, además de en otros aspectos en la creación de puestos de trabajo sostenibles, en preocupaciones ambientales y en prácticas ecológicas, contando todas ellas con certificaciones ISO 9001 y/o 14001. 
Situadas las firmas entrevistadas en el hipotético caso de que decidieran comprometerse con la preservación del medio rural, la mayoría de ellas apuesta por que las diferentes acciones o iniciativas se desarrollen de manera puntual ante una invitación o propuesta concreta de la ADR o el resto de instituciones implicadas.

Con relación a las distintas fórmulas de reconocimiento del compromiso con el medio rural que se sugieren (certificado, sello, premio, incentivo o distintivo de otro tipo) y si la existencia de algún tipo de reconocimiento aumentaría la implicación con el mantenimiento de un medio rural vivo las respuestas varían sustancialmente de una comarca a otra. En cualquier caso, las opiniones que justifican algunas de estas respuestas se repiten, por lo que consideramos interesante citar algunas de ellas:

- Certificado: mala acogida por identificarlo como algo gravoso y costoso para la empresa.

- Premios o sellos: efectos positivos a nivel de imagen pero limitados, tanto desde el punto de vista temporal como espacial (influencia estrictamente local y por tanto, poco interesante para empresas que operan a nivel internacional).

En general, se señala que estos certificados o premios no aportan diferenciación a la empresa ${ }^{16}$.

Por último, puede decirse que en general, la disposición ante este compromiso es positiva y prácticamente la totalidad de las empresas entrevistadas creen que merece la pena que se promueva la corresponsabilización de la empresa con el mantenimiento de un medio rural vivo aunque existe un consenso generalizado sobre la responsabilidad de la Administración en la promoción del compromiso de las empresas con el medio rural ${ }^{17}$.

16. Según recoge Canyelles (2006): «Tampoco creemos que el exceso de diversidad se deba resolver con una ISO. Respecto a la futura aparición de la norma ISO 26006, no queremos desdeñarla pero, a parte de que posiblemente no recogerá tan diáfanamente un sentido de compromiso, puede profundizar en un riesgo real, acabar reduciendo la complejidad».

17. Desde la convicción de que alcanzar este objetivo requiere contar con la corresponsabilidad no sólo de las empresas sino también de los inversores, consumidores, administraciones públicas, sociedad civil y educadores, nuestras iniciativas van dirigidas a que la empresa y aquellos que pueden influir sobre su comportamiento (Foro de expertos de la RSE, Ministerio de Trabajo y Asuntos Sociales, 2008). 


\section{La Administración ha de liderar la implicación de la empresa con el medio rural}

En base a los distintos análisis, reflexiones, sondeos y entrevistas realizadas se ha llegado a la conclusión de que el objetivo de avanzar en la corresponsabilización de la empresa con el medio rural tiene plena legitimidad, validez y posibilidad de obtener resultados. No obstante, a corto-medio plazo, consideramos que no sería factible, ni recomendable diseñar e intentar implantar un certificado de compromiso de la empresa con el medio rural.

El certificado se toparía con el obstáculo que supone la dominancia de la vertiente externa del compromiso (hacia la sociedad, hacia el entorno), aspecto que dificulta su formalización como herramienta que se incorpore a los sistemas de gestión de la empresa, como ocurre con otros sistemas de gestión como la ISO o EFQM.

El diseño y emisión de un certificado requiere un modelo muy estructurado y claro, con frecuencia ligado a estándares, difícil de compatibilizar con la diversidad de iniciativas que pueden ser valoradas como una contribución positiva de la firma al medio rural y que, en buena medida, vendrán determinadas por las necesidades particulares y específicas del medio rural de las distintas comarcas.

Un certificado requiere homologación de proveedores, un proceso de auditorias y por lo tanto implica unos costes. También requiere reconocimiento de la marca y notoriedad. A priori la repercusión y alcance de una marca de compromiso con el medio rural sería limitada comparativamente con los existentes.

Por otro lado, teniendo en cuenta también la opinión de las compañías existe una sensación de proliferación y cierta banalización de certificados, de etiquetas, etc. sin que perciba beneficio a corto plazo o repercusiones fácilmente demostrables y directas sobre su competitividad.

En cualquier caso, independientemente de que exista certificado o no, el trabajo desarrollado en el marco de este proyecto plantea la oportunidad de profundizar en la corresponsabilización del conjunto de la sociedad, y específicamente de la empresa, en el mantenimiento de un medio rural vivo ${ }^{18}$.

18. La Comunicación de la Comisión sobre desarrollo sostenible, aprobada por el Consejo Europeo de Gotemburgo, hizo hincapié en la importancia de la responsabilidad social de las empresas: «La actuación pública también desempeña un papel fundamental a la hora de crear una mayor sensación de responsabilidad social colectiva y de establecer un marco por el que las empresas deban integrar consideraciones ambientales y sociales en sus actividades. Debería animarse a las empresas a adoptar un enfoque proactivo 
Por todo ello, en base a los análisis y reflexiones realizadas, y a partir de la información obtenida de las firmas y de algunos suscriptores del Pacto Social y personalidades del mundo empresarial entrevistadas -que demuestran una actitud positiva y favorable hacia el avance en la corresponsabilización de las empresas y del conjunto de la sociedad con el mantenimiento del medio rural- el éxito en su implantación debería tener en cuenta la necesidad de hacer llegar al conjunto de la población la importancia del medio rural y el obligado dinamismo y participación de las entidades de desarrollo rural en la promoción de la iniciativa.

\subsection{El primer paso, concienciar a la sociedad}

Para que el impulso al compromiso de la empresa, y también de otros agentes sociales y del conjunto de la ciudadanía, con el medio rural pueda dar sus frutos en el medio-largo plazo y se asuma como algo natural consideramos que es imprescindible y urgente un plan de comunicación que permita subsanar las tradicionales carencias de apertura del medio rural al conjunto de la sociedad y desarrollar una labor de divulgación desde las instituciones de rango autonómico sobre:

- La importancia del medio rural y las aportaciones de éste al conjunto de la sociedad. Las encuestas realizadas han puesto de manifiesto que no existe una conciencia en el ámbito empresarial sobre la importancia del mantenimiento del medio rural, pero, ¿y en el resto de la sociedad? ${ }^{19}$.

- La empresa, el conjunto de la sociedad debe tener claro qué aporta el medio rural, que existe un riesgo de perder «cosas» insustituibles si desaparece el medio rural, etc.

- Evitar ese riesgo y seguir beneficiándonos de lo que nos aporta el medio rural requiere de la corresponsabilización del conjunto de la sociedad y de sus principales agentes.

En esta línea, es importante sustentar los mensajes en datos y argumentarlos con informaciones e indicadores objetivos, así como con testimonios de personas expertas e influyentes en nuestra sociedad, del mundo de la empresa, de la cultura, del medio ambiente...

Sin embargo, antes de comunicar es preciso elaborar el discurso. En este sentido creemos conveniente hacer una reflexión sobre el futuro del medio

en materia de desarrollo sostenible en sus operaciones, tanto dentro como fuera de la Unión Europea».

19. Ley 10/1998, de 8 de abril, de Desarrollo rural: [...] debe garantizarse una visión omnicompresiva del medio rural, de su problemática y de su multifuncionalidad [...]». 
rural, intentando definir la visión del medio para un horizonte temporal de 10-15 años. La definición de esta visión se considera imprescindible por parte de los agentes de desarrollo rural, en la medida en que orienta las políticas y estrategias a desarrollar, al tiempo que sirve de mensaje para aquellos que puedan tener la sospecha de que el mantenimiento del medio rural pueda ser un «empeño romántico», y que en un futuro el medio rural está abocado a quedar reducido a espacios naturales mejor o peor conservados, a una especie de maqueta o recuerdo del pasado. Es necesario explicar a la empresa, al resto de agentes sociales, de ciudadanos a los que se solicita la corresponsabilización que un medio rural vivo no sólo es posible, sino necesario para un desarrollo sostenible ${ }^{20}$.

La reflexión sobre el futuro del medio rural deberá desembocar en argumentos y valores renovados, claros y unívocos para su defensa y mantenimiento y la corresponsabilización en este reto del conjunto de la sociedad, los agentes sociales y económicos y el ciudadano particular.

Es preciso actualizar el mensaje hacia la empresa y hacia el conjunto de la sociedad (innovar y pensar en otros términos). Hay que tener en cuenta que la realidad y el comportamiento del medio rural va cambiando (desarrollo de urbanizaciones que permiten el asentamiento de población joven paliando el problema de despoblamiento en determinadas zonas, asentamiento de población inmigrante en el medio rural y ocupación en actividades agrarias), que existen contradicciones internas (generación de residuos de ciertas actividades primarias) y que las tendencias y transformaciones del entorno (globalización de mercados, de la cultura, de las exigencias de seguridad y calidad alimentaria, etc.) condicionan la percepción del medio rural por parte de la sociedad, su valoración y sus perspectivas de futuro.

Las bases sobre las que se ha sustentado la necesidad de una discriminación positiva hacia el medio rural deben ser a nuestro juicio revisadas teniendo en cuenta los cambios que se han producido no sólo en este espacio, sino en el conjunto de la sociedad, así como la imagen no siempre positiva que una parte de la sociedad puede tener de él (agricultores y ganaderos vistos como privilegiados que «viven de la subvención», «pluriempleados con lo

20. Miren Askasibar (2007) ya apunta que «una sociedad o un territorio que se rige por criterios sostenibles busca un presente y un futuro en el que los recursos humanos, la economía y el medio ambiente estén en un equilibrio que garantice la pervivencia de todos ellos. El medio rural es la herencia de la cultura y la forma de vida del caserío, que tradicionalmente se ha guiado por criterios de sostenibilidad, pues la máxima responsabilidad de quien lo dirigía era precisamente asegurar su pervivencia. Ahora, que los tiempos han cambiado, ¿qué significado tiene la sostenibilidad en el medio rural?, ¿cómo es el medio rural sostenible?». 
que generan fuertes ingresos», "propietarios de viviendas unifamiliares que pueden rehabilitar con ayudas en entornos inmejorables», etc.)

Para que se entienda la necesidad de compromiso de todos debe trasladarse una imagen ajustada a la realidad de lo que es el medio rural y de lo que supone vivir y trabajar en él, contrarrestando las imágenes negativas actualmente existentes en una parte de la sociedad. Es preciso eliminar cualquier duda sobre el valor social del compromiso.

Quizá haya llegado el momento de trascender mensajes de discriminación positiva hacia un medio y unas comunidades desfavorecidas y subrayar la vinculación del mantenimiento del medio rural con el futuro, con el desarrollo sostenible, con las exigencias y demandas crecientes desde el mercado y desde el conjunto de la sociedad por desarrollar comportamientos éticos y responsables con la comunidad y con el entorno. Se trata de avanzar hacia la corresponsabilización voluntaria, convencida y proactiva con el mantenimiento del entorno rural.

En el contexto del plan de marketing y comunicación que es preciso desarrollar y la necesaria corresponsabilización de todos en este reto, será preciso trasladar al conjunto de la sociedad las actuaciones y los logros que se vayan alcanzando, haciendo un especial énfasis en las actuaciones de la propia Administración: actuaciones coherentes, actuaciones ejemplarizantes, actuaciones conjuntas entre distintas administraciones y o departamentos de la Administración...

Finalmente, la importancia de este compromiso desde la perspectiva de equilibrio del territorio, va a requerir de las instituciones no sólo un apoyo a nivel de discurso, dando un valor social al compromiso, sino también la dotación de medios que hagan factible su efectiva implantación ${ }^{21}$.

21. A modo de ejemplo éstos son algunos de los instrumentos que utilizan los gobiernos para impulsar la RSE: desarrollo de un marco legislativo favorable; desarrollo de un marco fiscal favorable; instrumentos de financiación para empresas; medidas de transparencia (etiquetas e índices sociales) y reporting (memorias de sostenibilidad); concesión de premios; promover y difundir las buenas prácticas, promover, crear y supervisar mecanismos de evaluación, de verificación y certificación; dar apoyo económico y participar en iniciativas de partenariado público-privado-sociedad civil; generar mecanismos de crédito e inversión de las empresas en la comunidad o ventajas fiscales para empresas socialmente responsables; desarrollar campañas públicas para promover la RSE; crear departamentos o cargos públicos responsables de la RSE y programas interministeriales; crear foros multistakeholder, liderazgo por ejemplo; etc. 


\subsection{Las ADR como directoras de la acción de la empresa en el medio rural}

Centrándonos en el objetivo de avanzar en el compromiso de la empresa con el medio rural y la definición de un sistema que lo haga operativo, traduciéndolo en proyectos y actuaciones concretas, debemos de partir de la consideración del escaso conocimiento e implantación de la RSE en el tejido empresarial de las comarcas, así como la limitada apuesta de las instituciones por este modelo, al menos en el momento actual. Por ello consideramos que la obligación de la empresa con el medio rural debe ser, en principio, independiente de la RSE.

No obstante, para aquellas firmas familiarizadas con la RSE será importante transmitir los puntos en común existentes entre ambas, siendo el compromiso con el medio rural perfectamente coherente con la responsabilidad social empresarial, de tal manera que cualquier compañía que desarrollase actuaciones concretas en pro del medio rural pueda presentar estas acciones en su memoria de sostenibilidad. Teniendo en cuenta el respaldo con que cuenta la RSE a nivel internacional (están implicados organismos internacionales como la Comisión Europea, la ONU, gobiernos de distintos países y regiones, etc.) y la previsión de una extensión progresiva de su filosofía y modelo hacia el mundo empresarial será conveniente establecer los vínculos que se estimen oportunos entre ambas iniciativas de cara a reforzar y dar mayor proyección a la corresponsabilidad rural.

Es la presión social, la conciencia ciudadana la que hace entrar a la firma en compromisos ambientales (ISO 14001) o de otra índole, aparentemente alejados del más puro interés empresarial. Una vez aceptada la apuesta, ésta se transforma en un camino de no retorno. Es por ello que, habida cuenta de que las demandas de la sociedad y los grupos que demandan apoyo social son muy numerosos, el compromiso de la compañía con el medio rural debe orquestarse con una campaña de comunicación y sensibilización de gran repercusión a nivel social, liderarse desde la Administración y gestionarse a través de estructuras ya existentes vinculadas al territorio donde se asienta la empresa y al desarrollo del medio rural.

Atendiendo a la opinión generalizada de las compañias de que el compromiso de la empresa con el medio rural debe ser impulsado desde la Administración, proponemos que sea Landaberri quien lo lidere. Tal y como se expone en el artículo 9 de la ley de Desarrollo rural, Landaberri se constituye como órgano de colaboración y coordinación interinstitucional en materia de desarrollo rural, en cuyo seno se producen la cooperación y colaboración necesarias para la aplicación de la ley. Landaberri está adscrito al Departamento del Gobierno Vasco con atribuciones en el área de agricultura y desarrollo rural y 
está formado por representantes del Gobierno Vasco (ordenación del territorio, industria, etc.), las diputaciones forales y los municipios de la comunidad autónoma, ostentando la presidencia el consejero del Gobierno vasco responsable del área de agricultura y desarrollo rural.

En coherencia con el rol que la ley otorga a las Asociaciones de Desarrollo Rural $^{22}$, son éstas las estructuras más idóneas para ejercer el papel de interlocutor con el mundo de la empresa y establecer un diálogo y una comunicación abierta con la misma que facilite la asunción de compromisos y la concreción de actuaciones. Es preciso romper la actual situación de falta de relación, de diálogo entre el mundo rural y el mundo empresarial y que las Asociaciones de Desarrollo Rural de cada comarca (a modo de grupo de interés) transmitan a las compañías las necesidades del medio rural y las oportunidades de dar respuesta a éstas en la medida de sus posibilidades. En definitiva, desde las Asociaciones de Desarrollo Rural comarcales se debe hacer llegar a la firma los requerimientos y demandas para el mantenimiento del medio rural en sus respectivas comarcas y lograr que el compromiso con el entorno rural esté en la «agenda» de las empresas ${ }^{23}$.

Respecto al método o procedimiento a seguir para lograr la asunción por parte de la empresa de obligaciones concretas, los Programas de Desarrollo Rural comarcales son el instrumento más idóneo. Los PDR deben servir de vehículo de acercamiento de la empresa y del conjunto de la sociedad al medio rural, haciéndoles partícipes de su situación en la comarca y de sus perspectivas de desarrollo futuro. Asimismo, han de constituir el marco (visión, objetivos y estrategias) a partir del cual concretar proyectos e iniciativas que puedan ser desarrolladas por las empresas en cada una de las comarcas del País Vasco.

Respecto a la forma que ha de adoptar el compromiso de la empresa con el medio rural, como consecuencia de los análisis y sondeos realizados en el presente proyecto, se ha llegado a la conclusión de que debe tratarse de un compromiso voluntario, aunque no puntual y aislado, por lo que será preciso establecer una dinámica de trabajo con las empresas, desde las Asociaciones

22. La ley de Desarrollo rural 10/1998 de 8 de abril reconoce a las Asociaciones de Desarrollo Rural como instrumentos de participación y colaboración de los agentes económicos y sociales en las actuaciones de desarrollo rural de sus comarcas.

23. Una situación de la que aún estamos muy alejados. Como señalan los propios gerentes de las ADR el aspecto más criticado por todos los entrevistados es la falta de compromiso económico adquirido que respalde los PDR. Es más, según ellos, la política desarrollada no responde a las prioridades establecidas en los Planes de Desarrollo Rural. No ha habido un cambio significativo de su política presupuestaria, una situación extensible al resto de administraciones y departamentos. (Alberdi, 2004). 
Tabla 4. Pasos a cumplir en la concreción del compromiso de la empresa con el medio rural

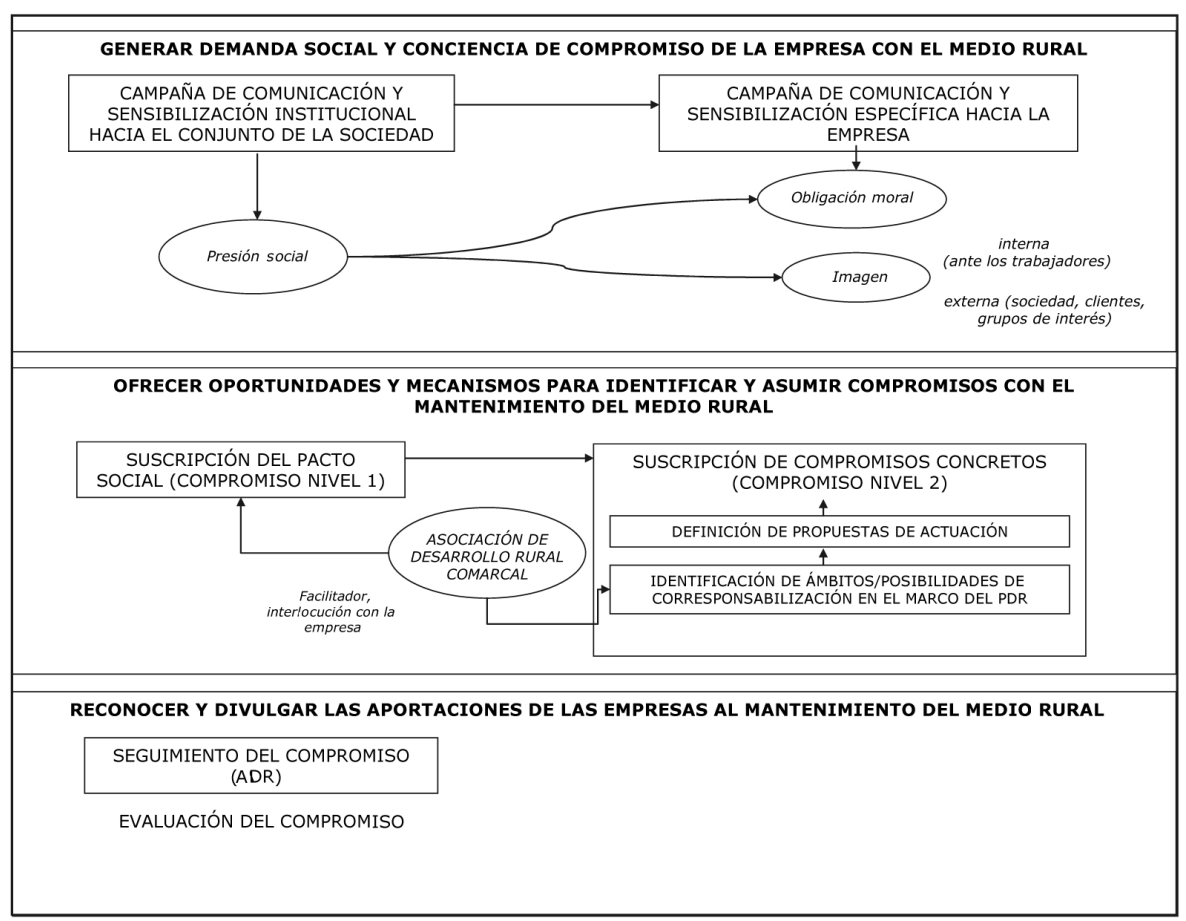

de Desarrollo Rural y en el marco de los Programas de Desarrollo Rural comarcales, desde su diseño hasta su ejecución, seguimiento y actualización.

Más allá de otros posibles incentivos que se pudieran arbitrar, en la medida en que la imagen, tanto interna como externa, es una de las principales motivaciones que pueden tener la mayoría de las firmas para asumir compromisos concretos con el medio rural, es necesario plantear algún tipo de reconocimiento que pueda tener una amplia repercusión en los medios de comunicación y llegar al conjunto de la sociedad. Ello favorecería a la empresa y al mismo tiempo a la necesaria labor de sensibilización y concienciación hacia el compromiso con el medio rural por parte de otras firmas y del conjunto de la sociedad ${ }^{24}$. Resumimos en la tabla 4 los pasos en los que se concreta el compromiso entre la empresa y el desarrollo rural.

24. Actualmente una labor similar se realiza en la promoción de los productos con label de la Comunidad Autónoma del País Vasco, mediante un concurso anual, en el que se destaca la labor de determinados agentes, personas y empresas en la promoción 
Habida cuenta del carácter innovador de la iniciativa y de la dificultad detectada a priori para identificar por parte de la firmas las posibilidades de contribuciones concretas al mantenimiento y desarrollo del medio rural será conveniente realizar una especie de guía o manual de buenas prácticas donde se les oriente e ilustre con ejemplos concretos las muy diversas posibilidades de apoyo desde la empresa al mantenimiento del medio rural.

\section{El medio rural, beneficiario de la corresponsabilidad empresarial: una labor difícil. A modo de conclusión}

Avanzar en la diversificación de actividades económicas es la única posibilidad que tienen hoy en día muchas zonas rurales para sobrevivir. La promoción del turismo se ha convertido, junto a la agricultura, en uno de los pilares básicos de muchas de nuestras economías rurales aunque otras actividades también contribuyen al desarrollo de estos espacios entre las que la industria, especialmente la agroalimentaria, ocupa un lugar destacado.

La multiplicidad de actividades ha de estar apoyada en una mejora de la calidad de vida de sus habitantes. Ello obliga a abordar nuevos campos de desarrollo, relacionados con la dotación de servicios, generalmente públicos, que, salvando las diferencias, equiparen la asistencia rural con la urbana. Guarderías, escuelas, ambulatorios, servicios sociales, etc. son prestaciones que se han de adecuar a las realidades de nuestras sociedades rurales y en las que la Administración pública ha de contribuir de manera decisiva.

Todo esfuerzo es necesario para asegurar la permanencia de un modelo medioambiental que ha de hacer frente a décadas de continua despoblación, a un alto índice de soltería, masculinidad y envejecimiento y a un modelo económico excesivamente dependiente de las vicisitudes del sector primario y, cada vez más, de las aportaciones de las arcas de la Seguridad Social.

Por ello, toda acción que contribuya a movilizar actividades y presupuestos para las zonas rurales ha de ser bienvenida, especialmente cuando contribuyen a impulsar propuestas de desarrollo endógeno. En este sentido, profundizar en la corresponsabilidad de la empresa con el desarrollo del medio rural es una iniciativa innovadora y con multitud de campos de aplicación en los espacios rurales.

La opción planteada, sin embargo, es un ejercicio difícil. Movilizar participación privada, de origen urbano, en proyectos rurales que, en todo caso, pueden ofrecerles imagen social es una tarea peliaguda. Las dificultades a superar

del producto local. Se concluye con un acto protocolario de gran repercusión en los medios de comunicación. 
son de lo más variado. En primer lugar porque son iniciativas novedosas, que nunca han sido planteadas o que en todo caso se han reducido a acciones muy puntuales. ¿Cómo concretarlas ahora en un programa continuado dirigido al conjunto del tejido empresarial?

El empresario muestra cada vez más preocupación por obtener certificados de calidad empresarial, laboral, ambiental... Éstos, sin embargo, han llegado a un punto de desarrollo y de saturación importante. ¿Cómo hacer atractivas las inversiones empresariales en el medio rural? ¿Qué les podemos ofrecer desde este medio?

Las estructuras de desarrollo rural, entidades creadas para aglutinar la participación pública y privada, son las organizaciones adecuadas para poner en marcha programas tan novedosos como el que plantamos. Éstas, sin embargo, se han dedicado a aportar subvenciones de origen público o, en el mejor de los casos, a promover iniciativas endógenas ligadas al desarrollo empresarial o a la dotación de servicios. ¿Cómo conseguir que estas estructuras sean capaces de contactar con un empresario o firma cuyo mundo desconocen?

Las interrogantes planteadas en torno a la viabilidad del proyecto son muchas, los esfuerzos personales y económicos a realizar en su puesta en marcha son importantes y los posibles resultados son una incógnita. A pesar de todas las dificultades, el medio elegido en la aplicación de la iniciativa es favorable.

Las comarcas del Deba, en particular, y el País Vasco en general, cuenta con una estructura empresarial muy arraigada, en gran medida de origen local, y en algunos casos de ascendencia rural. La cercanía entre el mundo rural y el urbano es inmediata. El caserío se desarrolla una vez superado el fondo del valle, su habitante acude diariamente a trabajar a la empresa próxima, el tiempo de ocio del urbano trascurre en buena medida en el medio rural que le rodea y la sensibilidad respecto a este medio es constatable. Todos ellos son aspectos que contribuyen a crear una posible opinión positiva en torno a la participación del mundo empresarial en el desarrollo del medio rural.

El esfuerzo merece la pena, la llegada de nuevos fondos es imprescindible y el derecho a fracasar es un atributo del agente de desarrollo rural. Por ello es importante continuar con la iniciativa y marcar un plan de trabajo para su materialización, programa que al menos ha de estar sustentado en los siguientes aspectos:

- Trasladar los resultados del trabajo desarrollado a la Consejería de Agricultura para recabar el máximo respaldo y liderazgo de la iniciativa.

- Desarrollar un plan de comunicación específico dirigido a la empresa. Definir los contenidos y diseñar los soportes divulgativos que clarifiquen la importancia del mantenimiento de un medio rural vivo incidiendo en 
las aportaciones del medio rural al conjunto de la sociedad y recojan las vías, mecanismos e instrumentos de apoyo con los que puede contar una empresa interesada en corresponsabilizarse con el mantenimiento del medio rural.

- Integrar la identificación de compromisos concretos de las empresas con el mantenimiento del medio rural proponiendo actuaciones concretas o solicitar propuestas de colaboración para el despliegue de las estrategias y objetivos en los que el compromiso de la firma puede ser más necesario.

- Diseñar el sistema de reconocimiento de las empresas que efectivamente hayan asumido compromisos concretos para el mantenimiento del medio rural dando la máxima difusión mediática al acto.

- Estudiar la posibilidad de otro tipo de incentivos como beneficios en tasas e impuestos y/o en procesos de contratación pública con la administración vasca.

- Trasladar a las instituciones, organizaciones y empresas implicadas con la RSE la posibilidad de canalizar algunos de sus compromisos y actuaciones hacia el mantenimiento del medio rural vasco a través de las ADR.

- Divulgar la iniciativa en foros locales, estatales e internacionales relacionados con el desarrollo rural, la sostenibilidad y la responsabilidad social empresarial.

El trabajo a realizar es arduo y los resultados que se puedan obtener de él, como hemos señalado, son una incógnita. Pero en un momento en el que los fondos dirigidos al desarrollo de las zonas rurales tienen fecha de caducidad las agencias de desarrollo han de buscar nuevas iniciativas y patrocinadores y el mundo de la empresa es una de las puertas que ha de abordar.

\section{Bibliografía citada}

AlBERDi, J.C. (2004): «Colaboración interinstitucional en el desarrollo rural: aciertos y fracasos de la ley de Desarrollo rural del País Vasco». Boletín de la Asociación de Geógrafos Españoles, no 33, pp. 7-30.

ASKASIBAR, M. (2007): Ordenación territorial del medio rural de Andoain, Oiartzun (Gipuzkoa). Inédito.

Benbeniste, S. (2002): El alcance del concepto de la Responsabilidad Social Corporativa de acuerdo a los organismos internacionales. Tesis doctoral inédita.

CANYelles, J.M. (2006): «Responsabilidad Social Empresarial: una idea de la responsabilidad global en España», [en línea] en <http://respsoem.blogspot. com/2006_10_08_archive html>.

Comisión de las COMUnidades Europeas (UE) (2001), Libro verde: Fomentar un marco europeo para la responsabilidad social de las empresas, [en línea] 
en <http://europa.eu.int/comm/employment_social/soc-dial/csr/greenpaper. htm>.

Corbera Millán, M. (1999): «Las políticas de desarrollo rural en la región Cantábrica: los programas LEADER», en Cambios en los espacios rurales cantábricos tras la integración de España en la UE, Universidad de Cantabria, pp. 175-237.

Cruz OrozCo, J. (1996): «Desarrollo rural y políticas públicas en las zonas de montaña del País Valenciano», VIII Coloquio de Geografía Rural. Jaca, pp. 53-68.

DiRECCIÓN GENERAL DE EMPRESAS DE LA COMISIÓN EUROPEA (2008): Responsabilidad social de las empresas, [en línea] en <http://www.telvill.hu>.

ECOlOGía y DeSARROllo (2008): Programa de economía y responsabilidad social empresarial (Ecores), [en línea] en <http://www.ecores. org >.

Foro de Expertos de la RSE. Ministerio de Trabajo y Asuntos Sociales (2008): Responsabilidad social de las empresas: tipos de responsabilidades y plan de actuación, [en línea] en <http://www.mtas.es/insht/ntp/ntp_644.htm>.

FRIEDMAN, M. (1994): La teoría de los precios, Ediciones Altaya.

GLOBAL REPORTING INITIATIVE (GRI) (2000): Sustainability reporting guidelines, [en línea] en <http://www.globalreporting.org/GRIGuidelines/June2000/June2000GuidelinesDownload.htm>.

GLOBAL REPORTING INITIATIVE (GRI) (2002): Draft 2002 sustainability reporting guidelines, [en línea] en <http://www.globalreporting.org/GRIGuidelines/2002draft. htm>.

Mendikoi (1998): Plan de desarrollo rural de las comarcas de Montaña Alavesa, Valles Alaveses, Rioja Alavesa, Estribaciones del Gorbea, Cantábrica Alavesa, Llanada Alavesa, Enkarterrialde, Arratia Nervión, Tolosaldea-Urola Kosta, Departamento de Agricultura del Gobierno vasco, Vitoria, inédito (formato CD).

- (2002): Plan de desarrollo rural de las comarcas de Durangaldea, Uribe, Busturialdea, Lea-Artibai, Debabarrena, Donostialdea, Goierri, Debagoiena, Departamento de Agricultura del Gobierno vasco, Vitoria, inédito (formato CD).

- (2003): Ley de Desarrollo rural y Programas de Desarrollo Rural. Jornadas de reflexión, 14, 15, 18 y 24 de julio de 2003, Departamento de Agricultura del Gobierno vasco, Vitoria, inédito, 289 pp.

Organization For ECONOMIC CO-Operation AND DEVElopment (OECD) (2001): Corporate social responsibility, partners for progress sustainability, http://www. oecd-prg/dpci,emt/37/0,3343.

ReInOSO, D. y J. SANCHO, (2002): «Equipamientos y servicios en la Sierra Norte de Guadalajara: un diagnóstico basado en la participación social», X Coloquio de Geografía Rural, Santander, pp. 772-779.

WiKIPEDIA: Responsabilidad Social Corporativa, [en línea], <http://es.wikipedia. org/wiki/Responsabilidad_social_corporativa>. [Consulta: 8/04/2008]. 